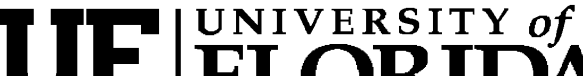 FLORIDA \\ IFAS Extension
}

\section{Effective Bat Houses for Florida ${ }^{1}$}

Holly K. Ober ${ }^{2}$

Bats can be a beneficial addition to the wildlife community on your property. With the exception of a few uncommon bats in the Florida Keys, all resident bats in Florida eat insects. Bats reduce common insect pests by consuming them in large quantities and the sound of bat calls can repel additional insects from areas where bats spend time. By attracting bats to your farm, forest, or backyard you may substantially reduce the number of nocturnal insects nearby.

\section{Attracting Bats to Your Property}

All insect-eating bats need roost sites in which to sleep during the day. Several of the 13 species of bats that live in Florida year-round select warm, dry, dark, narrow crevices for roosting. You may be able to attract these bats to your property by putting up wooden bat houses with appropriately-sized crevices (Figure 1). The two species you are most likely to attract to bat houses in Florida are the Brazilian free-tailed bat (Tadarida brasiliensis) and the evening bat (Nycteceius humeralis). Other less common tenants of bat houses in Florida are the southeastern bat (Myotis austroriparius) and the big brown bat (Eptesicus fuscus). Each of these species consumes insects that are known pests to crops.

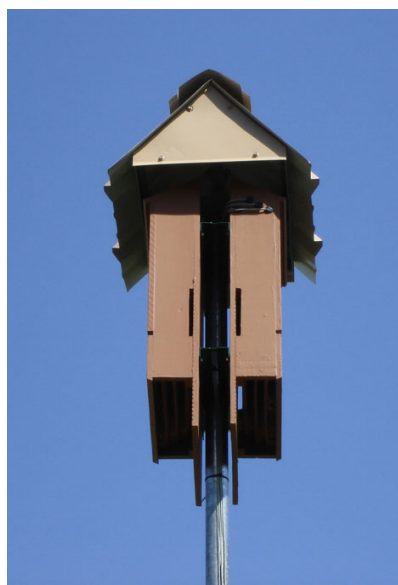

Figure 1. Two 4-chamber bat houses mounted back-to-back on a pole and covered with a metal roof provide roosting habitat for bats. Credits: Holly Ober (2008).

Research conducted by Bat Conservation International (http://www.batcon.org) has determined bat house characteristics that bats find most attractive. Bat houses with chambers at least 14 inches wide and at least two feet tall have a greater chance of attracting bats than narrower or shorter houses (Figures 2-5). A landing area beneath the entrance at least three inches long with a rough surface for bats to grab onto when they fly to the house is critical for facilitating access. If a bat house has only one chamber for bats to roost in, roughen the entire back panel of the interior of the house so that

1. This document is WEC246, one of a series of the Wildlife Ecology and Conservation Department, Florida Cooperative Extension Service, Institute of Food and Agricultural Sciences, University of Florida. Original publication date August 2008. Visit the EDIS Web site at http://edis.ifas.ufl.edu.

2. Holly K. Ober, assistant professor and extension specialist, Department of Wildlife Ecology and Conservation, University of Florida, IFAS, at the North Florida Research and Education Center, 155 Research Rd, Quincy, Fl 32351

The Institute of Food and Agricultural Sciences (IFAS) is an Equal Opportunity Institution authorized to provide research, educational information and other services only to individuals and institutions that function with non-discrimination with respect to race, creed, color, religion, age, disability, sex, sexual orientation, marital status, national origin, political opinions or affiliations. U.S. Department of Agriculture, Cooperative Extension Service, University of Florida, IFAS, Florida A. \& M. University Cooperative Extension Program, and Boards of County Commissioners Cooperating. Larry Arrington, Dean 
bats can easily grab onto the surface with their toes. If the house has more than one roosting chamber, roughen at least one side of each of the partitions separating the chambers.

There are two ways to provide rough surfaces within the house and on the landing pad: score or groove the surface using a saw or other sharp implement to make shallow cuts, or staple durable plastic mesh firmly to the wood. In Florida, grooving the surfaces is highly preferable to stapling on plastic mesh because high humidity often causes the wood to warp and the mesh to sag. Over time bats may not be able to use houses with warped wood and plastic mesh. If you cut grooves, position them horizontally at 1/4- to $1 / 2$-inch intervals and cut them no more than $1 / 16$ inch deep. If you cannot cut grooves in the wood, UV-resistant plastic mesh (1/8 to $1 / 4$ inch) is the next best option. Avoid hardware cloth and metal mesh because they could injure bats, and stay away from nylon or fiberglass window screening because these materials deteriorate quickly. Staples for holding the mesh to the wood should be exterior grade or galvanized and should not protrude from the wooden panels.

The color of the exterior of a bat house is an important consideration because it influences the temperature inside the house, and bats select roost sites according to interior temperatures. After you caulk all the seams, paint your bat house with three coats of flat, exterior-grade, water-based paint or stain to increase its lifespan. Two characteristics of the location where the house will be mounted influence which paint color would be best: the temperature and the number of hours of direct sun exposure. A house in north Florida located in a spot that receives direct sunlight for only a few hours each day should be painted a dark brown or dark gray, whereas a light brown or gray would be more appropriate for a site in south Florida with a lot of sun. Darker colors absorb heat from the sun, whereas lighter colors reflect heat from the sun.

Bat houses made from a combination of exterior plywood and cedar work well; pressure-treated wood should be avoided because it may be toxic to bats. Plywood should be exterior-grade (ACX, BCX, or T1-11 grade), and plywood used on the exterior should be at least $1 / 2$ inch thick for durability. Interior plywood partitions can be $3 / 8$ inch thick rather than $1 / 2$ inch to reduce the weight of the house. Screws are preferable to nails because they last longer. All screws and staples should be exterior-grade (galvanized or stainless).

Bats prefer houses that do not allow rainwater to seep in. Careful caulking of all seams (with latex caulk) can prevent leaks. Re-caulk every three to five years during a time of year when bats are not present. Some houses may be used continuously by bats for long periods each year, whereas other houses may receive intermittent use throughout the year. To determine a time of year when bats are not using the house, shine a flashlight or spotlight up into the house from below during daylight hours and check for occupants. Do not take the house down for recaulking when bats are present.

Although it is important that houses are watertight, bat houses in Florida should not be airtight, due to warm temperatures. A single, 1/2-inch-wide vent placed horizontally along the entire front of the house about 6 inches from the bottom can promote airflow. Vents 6 inches tall and $1 / 2$ inch wide on the side of the rear chamber can also increase air circulation. Shingles or sheet metal over the roof can increase longevity of the house. A roof that provides a wide overhang will provide some shade during the middle of the day, reducing the chance that bats could overheat.

Bat houses can be put up any time of year. However, bats are most likely to move in during the early spring, so it is best to put up houses during the winter so they are available when bats are actively searching for roosts. If bats are being excluded from a building and bat houses are being provided as alternative roost sites, they should be put up several weeks before the eviction.

Many myths exist regarding techniques to attract bats to new bat houses. One common myth is that bats can be lured into a new bat house by painting it with guano from other bats. Research indicates that this does not work. Some folks believe that playing recordings of bat calls can lure bats to a new house, but this also has not proven to be true. Another common myth is that capturing a bat and relocating it 
to a new bat house will encourage other bats to relocate. In reality, placing a bat in a new house is unlikely to result in permanent use of the house by that bat or any others. In any case, it is illegal to capture and relocate bats without a permit in Florida. Bats are wild animals that should never be handled since they are likely to bite in self defense and bites could transmit a disease such as rabies (http://edis.ifas.ufl.edu/UW282).

\section{Selecting a Location for Your Bat House}

Bat houses located on the sides of buildings or on poles are more likely to attract bats than bat houses mounted on trees. This is because houses on trees tend to be shaded by foliage and tend to provide perch sites for predators, both of which are bad for the bats. Poles and buildings are better alternatives because they offer more exposure to sunlight and fewer perch sites for potential predators such as owls, hawks, and falcons. Bat houses should be located at least 20 feet from potential perch sites for predators and at least 12 feet off the ground. If mounted on a metal or wooden pole, a conical piece of flashing wrapped around the pole can prevent potential predators (such as snakes) from climbing the pole.

Again, bats will not use houses where the internal temperature is too hot or too cool. The length of time the house is exposed to direct sunlight during the course of an average day influences its temperature. You can control the temperature through the orientation of the bat house on the side of a building (north, south, east, west), and the presence of an awning that provides shade over the house. Other factors that influence bat house temperatures include the color of the paint or stain on the exterior of the house, the material used to construct the house, and the amount of ventilation. Most bats prefer interior temperatures from 80 to $100^{\circ} \mathrm{F}$.

Bats select roost sites that are near the other resources they require, such as food and fresh water. Bat houses in areas with a mix of habitat types, such as woods and agricultural fields, typically have the greatest likelihood of attracting bats due to the diversity of feeding opportunities. Many bats drink free-standing water shortly after emerging from their roost at dusk and several species consume insects commonly found near water. For this reason, bat houses located within 1/4 mile of a river, stream, pond, or lake are more likely to be used than houses located farther from water.

It is best to select a location for your bat house that will be permanent because you won't want to move a house once bats have settled in. Because guano (bat droppings) will accumulate beneath the house once bats take up residence, it is wise to select a location where the sight or odor of droppings will not be bothersome. To reduce the odor produced by large quantities of guano, this material can be scooped up periodically and used as a fertilizer for plants. Guano should be collected with a shovel or scoop rather than with bare hands to avoid direct contact with microorganisms living in the feces.

\section{How To Mount Your Bat House}

If you plan to mount your bat house on the side of a building, structures made of wood, brick, or stone are a much better choice than buildings with metal siding. For single-chamber houses, building mounts are preferable to tree or pole mounts because the building will provide some buffer from rapid changes in air temperatures. Multi-chamber houses can be mounted on buildings or poles. Options for mounting bat houses on buildings include using several 1" x 2" wooden rails placed either horizontally or vertically on the rear of the bat house, slightly longer than the dimensions of the house.

Alternatively, houses could be mounted using 2-inch by 4 -inch wooden boards and French cleats.

If you decide to mount your house on a pole, you could use either a 4-inch x 6-inch pressure-treated post or a metal pole. The post should be at least 16 feet long so that the house is an adequate height off the ground after the post has been dug 3 feet into the ground. Smaller houses can be mounted on a single wooden post by attaching a wooden cross made of 2-inch by 4-inch boards, or to a metal pole using U-bolts. Larger houses or back-to-back houses can be mounted to double posts (one post at each end of the houses). Two bat houses mounted back-to-back on a single or double pole arrangement offer a variety of temperature conditions for roosting bats, especially 
when they are covered with a single galvanized metal roof to provide additional roosting space between the two houses.

\section{Common Reasons Bat Houses Do Not Attract Bats}

Bat houses serve as a place for bats to stay warm, dry, and undisturbed while sleeping during the day. If a bat house does not provide the temperatures bats find comfortable, they will never inhabit the house. If a house has been up for three or more years and no bats have moved in, you may be able to make the house more attractive by changing either the color of the exterior or the location of the house. Light and noise can be disruptive to bats, so houses should not be mounted near bright lights or near areas with a lot of human activity.

Houses with multiple chambers are generally more successful at attracting bats than single-chamber houses. Houses with more chambers provide living space with a variety of temperatures, allowing the bats to select the conditions most comfortable for them. Similarly, short, narrow houses provide less variation in temperatures than tall, wide houses, and are therefore less attractive to bats than are larger houses. Very small houses are unlikely to ever attract inhabitants.

Finally, bat houses require periodic maintenance. Check periodically for wasp and mud dauber nests. If mud daubers do make mud nests inside your bat house when bats are not present, these nests can be scraped out with a long, thin pole or hosed out with a high pressure garden hose. Insecticides are not needed, and they are strongly cautioned against because they would likely prevent future use of the house by bats. Remember to re-caulk to prevent drafts and leaks. If you use mesh, it may need replacement after several years of use.

\section{Concerns about Attracting Bats to Yards}

The only animals other than bats that could be attracted to your property by a bat house are insects such as wasps and mud daubers that consider dark crevices good locations for nests. Avoid chambers more than 3/4 inch wide because they are more likely to attract wasps and less likely to attract bats.

The presence of bats in your yard is unlikely to influence the use of your yard by birds, because birds and bats are active at different times of day and they rely on different insects for food.

Children should be warned never to touch bats (and all other wild animals). Healthy bats are rarely found on the ground, so if you find a bat on the ground, you should assume it to be ill and not pick it up. Call a local animal rehabilitation center or your County Animal Control if you find an injured bat. Do not bring a bat or any other wild animal into your home to care for it yourself.

\section{Additional Information}

Allen, G. M. and M. B. Main. 2004. Bats of Florida. University of Florida, IFAS Extension document available at http://edis.ifas.ufl.edu/UW203.

Kern, W. H. 2005. Bats in Buildings. University of Florida, IFAS Extension document available at http://edis.ifas.ufl.edu/MG342.

Marks, C. S. and G. E. Marks. Bats of Florida. 2006. University Press of Florida. Gainesville, Fl. $176 \mathrm{pp}$.

Ober, H. K. and F. J. Mazzotti. 2008. Conservation of Bats in Florida. University of Florida, IFAS Extension document available at http://edis.ifas.ufl.edu/UW291.

Ober, H. K. 2008. Insect Pest Management Services Provided by Bats. University of Florida, IFAS Extension document Conservation of Bats in Florida available at http://edis.ifas.ufl.edu/UW289.

Ober, H. K. 2007. Protecting your family and pets from rabies. University of Florida, IFAS Extension document available at http://edis.ifas.ufl.edu/UW282.

Tuttle, M. D., M. Kiser, and S. Kiser. 2004. The bat house builder's handbook. Bat Conservation International available at http://www.batcon.org. 


\section{Figure 2.}

Materials (makes one house)

1/s sheet $\left(2^{\prime} \times 4^{\prime}\right)$ 1/" AC, BC or T1-11 (outdoor grade) plywood One piece $1 " \times 2 "$ " $\left(3 / " \times 1 / 2 "\right.$ finished) $\times 8^{\prime}$ pine (furring strip)

20 to 30 exterior-grade screws, $1 "$

One pint dark, water-based stain, exterior grade

One pint water-based primer, exterior grade

One quart flat, water-based paint or stain, exterior grade

One tube paintable latex caulk

$1^{\prime \prime} \times 4 " \times 28$ " board for roof (optional, but highly recommended)

Black asphalt shingles or galva ni zed metal (optional)

6 to 10 roofing nails, $7 \mathrm{~s}^{\prime \prime}$ (if using shingles or metal roofing)

\section{Recommended tools}

Table saw or handsaw

Variable-speed re versing drill

Screndriver bit for drill

Tape measure or yardstick

Caulking gun

Paintbrushes

Hammer (optional)

Tin snips (optional)

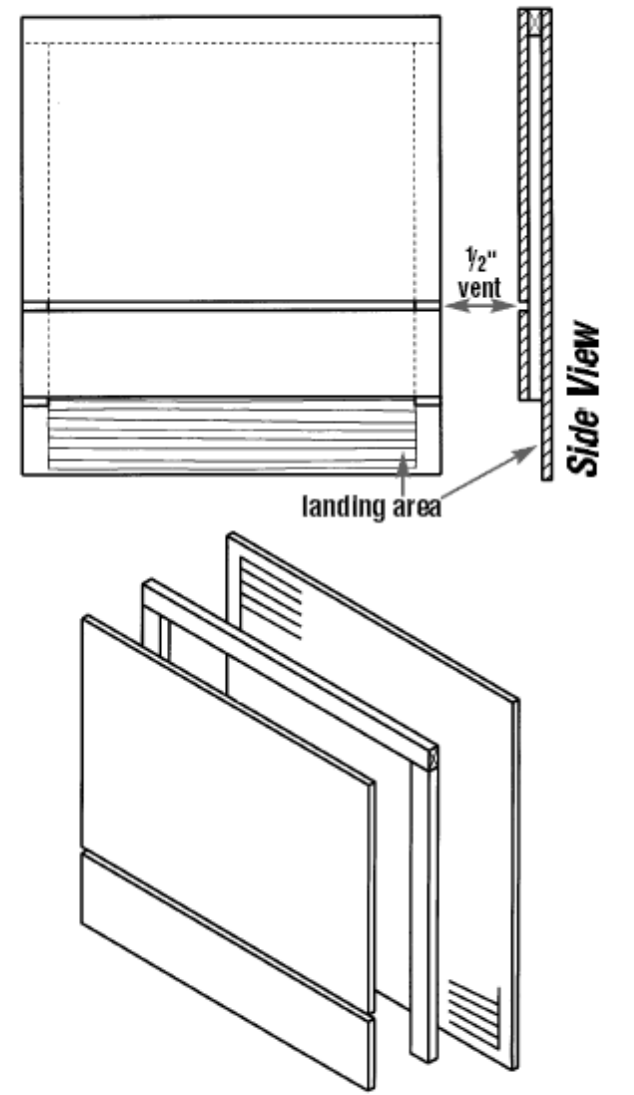

More bat-house plans and additional information can be found in BCl's Bat House Builder's Handbook available at wmwbatcatalog.com.

\section{Construction}

1. Measure and cut plywood into three pieces: $261^{\prime \prime} \times 24^{\prime \prime} \quad 161^{\prime \prime} \times 24^{\prime \prime} \quad 5^{\prime \prime} \times 24^{\prime \prime}$

2. Roughen inside of backboard and landing area by cutting horiantal grooves with sharp object or saw. Space grooves $1 / 7 "$ to $1 / 2 "$ apart, cutting $1 / 32 "$ to $1 / 6$ " deep.

3. Apply two coats of dark, water-based stain to interior suffaces. Do not use paint, as it will fill grooves.

4. Cut furring strip into one $24^{\prime \prime}$ and two $20 \frac{1}{2}$ " pieces.

5. Attach furring strips to back, caulking first. Sta rt with 24" piece at top. Roost chamber spacing is $3 /$.

6. Attach front to furring strips, top piece first (caulk first). Leave $1 / 2 "$ vent space between top and bottom front pieces.

7. Caulk all outside joints to further seal roost chamber.

8. Attach a 1" $\times 4$ " $\times 28$ " board to the top as a roof (optional, but highly recommended).

9. Apply three coats of paint or stain to the exterior (use primer for first coat).

10. Cover roof with shingles or galvanized metal (optional).

11. Mount on building (south or east sides usually best).

\section{Optional modifications to the single-chamber bat house}

1. Wider bat houses can be built for larger colonies. Be sure to adjust dimensions for back and front pieces and ceiling strip. $\mathrm{A} \mathrm{X}^{\prime \prime}$ support spacer may be needed in the center of the roost ing chamber for bat houses over 24" wide to pre vent warping.

2. To make a taller version for additional temperature diversity, use these modifications: From a 2' x 8' piece of plywood, cut th re pieces: $51^{\prime \prime} \times 24^{\prime \prime}, 33^{\prime \prime} \times 24^{\prime \prime}$ and $12^{\prime \prime} \times 24^{\prime \prime}$. Cut two $8^{\prime}$ furring strips into one $24 "$ and two $44 "$ pieces. Follow assembly procedure above.

3. Two bat houses can be placed back-to-back, mounted between two poles, to create a three-chamber nursery house. Before assembly, cut a horizontal $\mathrm{k} /$ " slot in the back of each house about 9 " from the bottom edge of the back piece to permit movement of bats between houses. Two pieces of wood, $1^{\prime \prime} \mathrm{x}$ $4^{\prime \prime} \times 4{ }^{\prime \prime}$, screwed horizontally to each side, will join the two boxes. Leave a $\bar{X}^{\prime \prime}$ space between the two houses, and roughen the wood surfaces or cover the back of each with plastic mesh (see item 5 below). Do not cover the rear exit slots with mesh. One 1" x 4" x 34" ve rrical piece, attached to each side over the horizontal pieces, blocks light but allows bats and air to enter. A galvanized metal roof, covering both houses, protects the center roosting area from rain. Eaves should be about $3^{\prime \prime}$ in southern areas and about $1 / 2 "$ in the north.

4. Ventilation may not be necessary in cold climates. In this case, the front should be a single piece 23 " long. Smaller bat houses like this one will be less successful in cool climates. However, those mounted on buildings maintain thermal stability better and are more likely to attract bats.

5. Durable plastic mesh can be substituted to provide footholds for bats. Attach one $20^{\prime \prime} \times 24 \%^{\prime \prime}$ piece to backboard after staining interior, but prior to assembly. 
Figure 3.

\section{Four-chamber Nursery House}

Materials (makes two bouses) - Diagrams on pages $12 \& 13$ $1 / 2$ sheet $\left(4^{\prime} \times 4^{\prime}\right) 1^{1 / 2} \mathrm{AC}, \mathrm{BC}$ or T1-11 (outdoor grade) plywood $1 / 2$ sheet (4' x 4') $y^{\prime \prime}$ AC or BC (outdoor grade) plywood Two pieces $1 " \times 6^{\prime \prime}\left(3^{\prime \prime} \times 5^{1 / 2}\right.$ " finished) $\times 8^{\prime}$ pine or cedar One lb. coated deck or exterior-grade screws, $1 \gamma^{\prime \prime}$

20 to 25 coated deck or exterior-grade screws, $1 \mathrm{H}^{\prime \prime}$

20 to 25 exterior-grade screws, 1 "

One quart dark, water-based stain, exterior grade

One quart water-based primer, exterior grade

Two quarts flat water-based paint or stain, exterior grade

One tube paintable latex caulk

Black asphalt shingles or galvanized metal

12 to 20 roofing nails, $7 / \mathrm{g}^{\prime \prime}$

\section{Recommended tools}

Table saw or circular saw

Variable-speed reversing drill

Screwdriver bit for drill

Tape measure or yardstick

Caulking gun

$1 \frac{1}{2 \prime \prime}$ hole saw or spade bit

\section{Paintbrushes}

Hammer (optional)

Tin snips (optional)

Bar clamp (optional)

Sander (optional)

\section{Construction}

1. Measure, mark and cut out all wood according to the sawing diagrams on pages 12 and 13 .

2. Roughen interior and landing surfaces by cutting horizontal grooves with sharp object or saw. Space grooves $1 /{ }^{1 / 2}$ to $\frac{1 / 2}{2}$ apart, cutting $1 / 3_{2} "$ to $1 / 66^{\prime \prime}$ deep.

3. Apply two coats of dark, water-based stain to interior surfaces. Do not use paint, as it will fill grooves.

4. Artach side pieces to back, caulking first. Use 15/" screws. Make sure top angles match.

5. Artach $5 "$ and $10^{\prime \prime}$ spacers to inside corners per drawings on page 12. Use 1" screws. Roost chamber spacing will be $3 / 4$ (front to back). Do not block side vents.

6. Place first roosting partition on spacers even with bottom edge of roof. Place 20 " spacers on partition and screw to first spacers (through partition), using $1 \%$ " screws.

7. Repeat step 6 for remaining spacers and partitions.

8. Artach front to sides, top piece first (caulk seams). Be sure top angles match (sand if necessary). Leave $1 / 2$ " vent space between top and bottom front pieces. A bar clamp may be useful if sides have flared out during construction.

9. Artach roof supports to the top inside of front and back pieces with 1" screws. Don't let screws protrude into roosting chambers.

10. Caulk around all top surfaces, sanding first if necessary to ensure good fit with roof.

11. Attach roof to sides and roof supports with $1 \frac{1 \%}{1}$ screws. Caulk around roof and side joints to further guard against leaks and drafts. Don't let screws protrude into roosting chambers.

12. Paint or stain exterior three times (use primer for first coat).

13. Cover roof with shingles or galvanized metal.
Optional modifications

1. These nursery-house dimensions were chosen to permit construction of two bat houses per halfsheet of plywood. Increasing house width to $24 "$ or more or adding partitions benefits bats and attracts larger colonies. Additional spacers are required to prevent warping of roost partitions for houses more than $24^{\prime \prime}$ wide.

2. Taller bat houses provide improved temperature gradients and may be especially useful in climates where daily temperatures fluctuate widely. Bat houses 3' or taller should have the horizontal vent slot $12^{\prime \prime}$ from the bottom of the roosting chambers.

3. Two bat houses can be placed b a ck - to - b a ck mounted on poles. Before assembly, a horizontal $\mathrm{K}^{\prime \prime}$ slot should be cut in the back of each house about $10^{\prime \prime}$ from the bottom edge of the back piece to permit movement of bats between houses. Two pieces of wood, 1" x 4" x 103", screwed horizontally to each side, will join the two boxes. Leavea $\mathcal{B}^{\prime \prime}$ space between the two houses, and roughen the wood surfaces or cover the back of each with plastic mesh. One 2" x 4" x 40" ve rtical piece, attached to each side, over the horizontal pieces, blocks light but allows bats and air to enter. Use a $2 " \times 6$ " ve rtical piece if securing houses with Ubolts to metal poles. A galvanized metal roof that covers both houses protects them and helps pre vent overheating. Eaves should extend about $3^{\prime \prime}$ in front in southern areas and about $1 \frac{1 / 2}{\prime \prime}$ in the north.

4. Ventilation may not be necessary in cold climates. In that case, the front of the bat house should be a single, 23"-long piece. Far-northern bat houses may also benefit from a partial bottom to help retain heat. Slope the sides and bottom at an angle of $45^{\circ}$ or greater to reduce guano build-up. Leave a $x^{\prime \prime}$ entry gap at the back and be sure the bottom does not interfere with access to the front crevices. A hinged bottom is required to permit annual cleaning.

5. Durable plastic mesh can be substituted for roughening. Attach mesh to backboard, landing area and one side of each partition after staining interior, but prior to assembly. Use 1/8"or $1 / "$-inch HDPE plastic mesh [such as Internet product \#1672 (1-800-328-8456; www.internetmesh.net)] and attach every two inches with "/6" Monel ${ }^{\circledR}$ or stainless steel staples.

6. Make partitions removable by attaching small cleats with thumbscrews to the bottom of side pieces for support. Spacer strips are unnecessary if grooves for partitions are cut in the side pieces with a router or dado saw blade. 

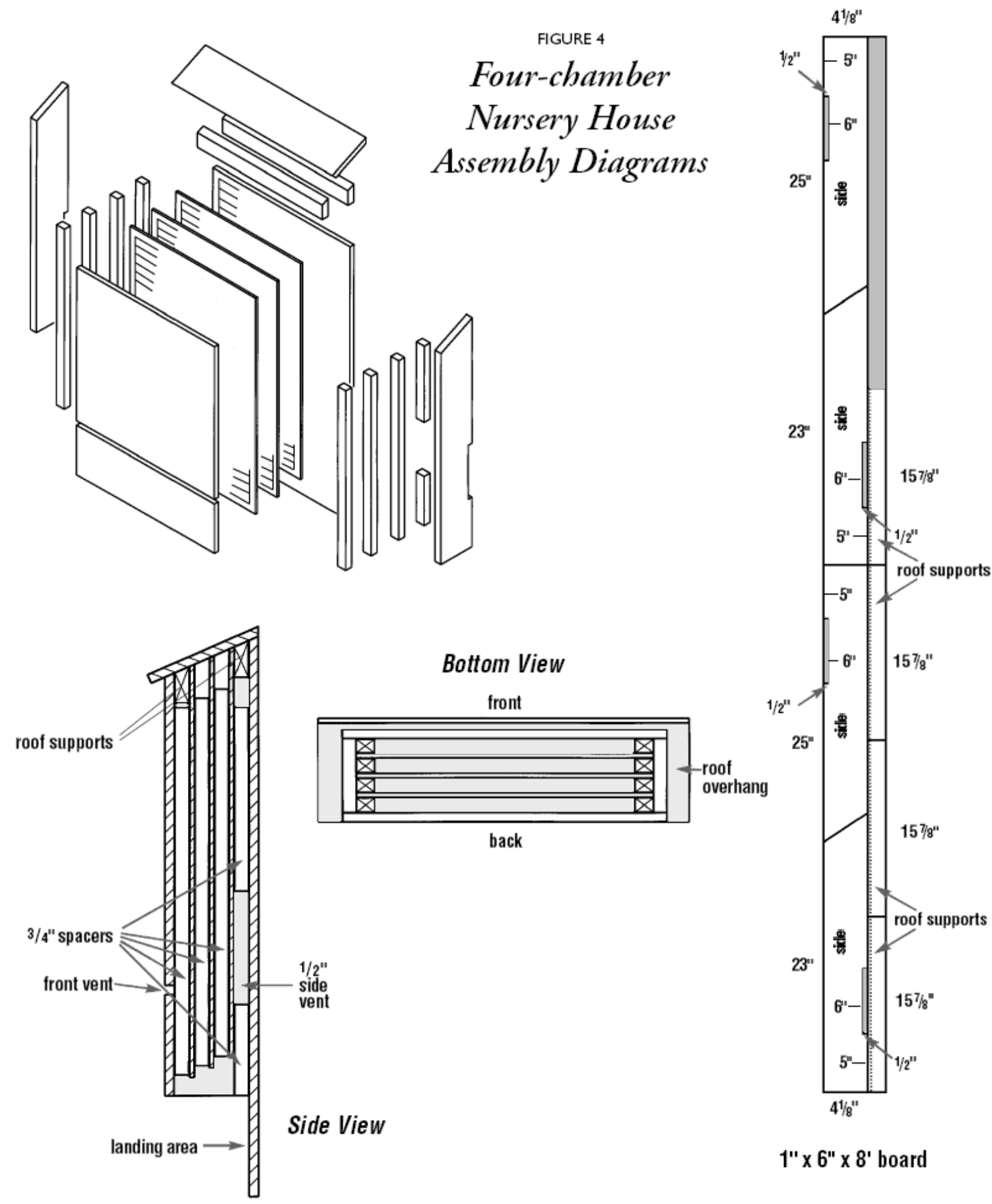

$1 " \times 6 " \times 8$ ' board 


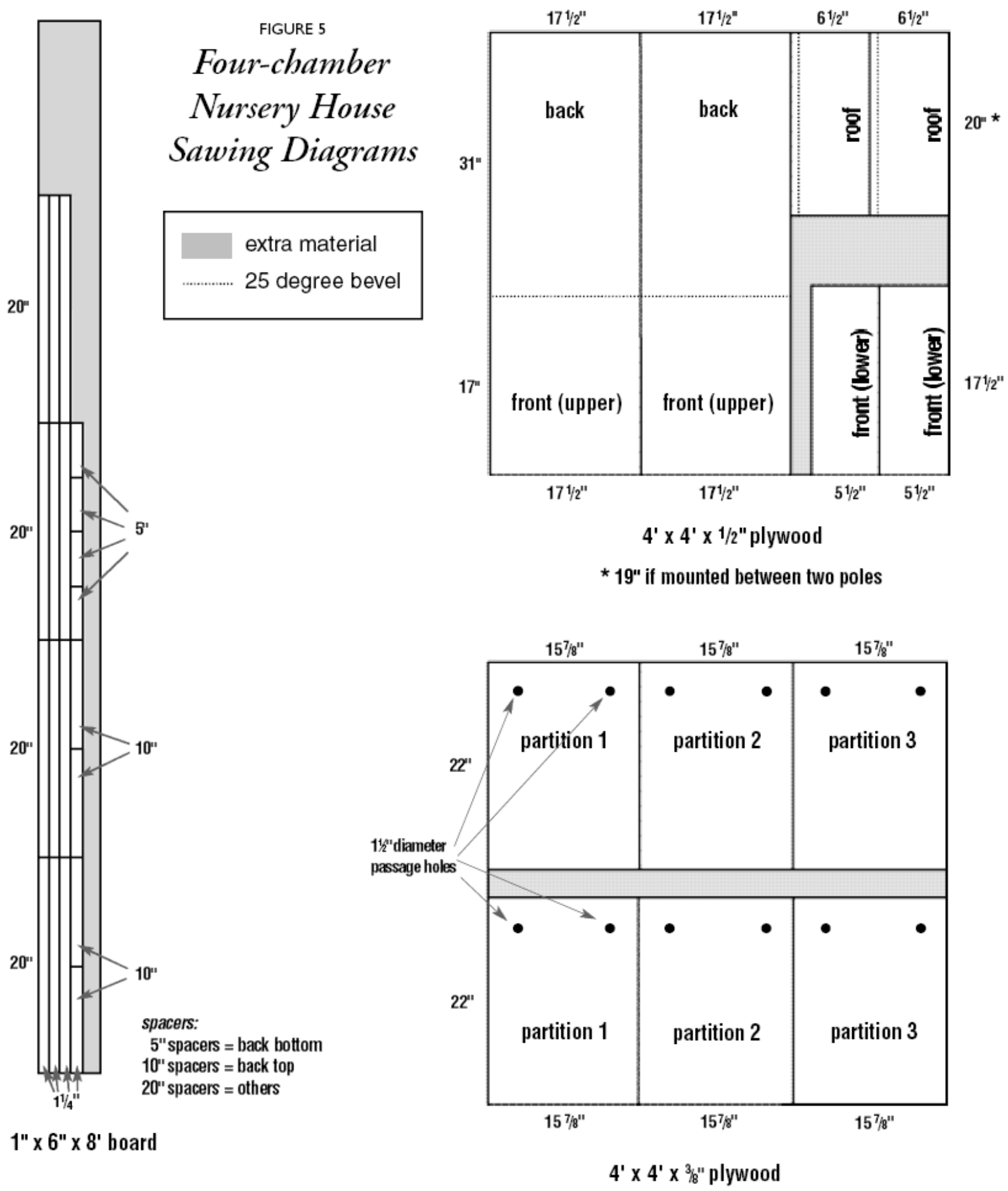

